\title{
A NEGATIVIDADE COMO FUNDAMENTO E A CATÁSTROFE COMO DEVIR: REFLEXõES PRIMÁRIAS PARA UM MÉTODO
}

\author{
Márcio Rufino Silva*
}

Resumo: A crise e sua leitura comporta necessariamente o sentido da negatividade, como método e possibilidade de se compreender seus termos e sua extensão. A negatividade, movimento próprio da sociabilidade posta pela forma valor, irrompe a premissa de que o espaço, proposto enquanto simultaneidade e reposição dos termos do valor, se apresenta enquanto estratégia de rearranjo do estado crítico. Assim, a crise, redundando ao nível do possível na catástrofe, encontraria na governança a sua manutenção enquanto estado crítico, instaurando o ideário da administração da crise e, negativamente, aprofundando-a em direção ao catastrófico.

Palavras-chave: estado crítico; catástrofe; governança; negatividade; simultaneidade.

\section{NEGATIVITY AS BACKGROUND AND CATASTROPHE AS DEVIR: REFLECTIONS FOR A PRIMARY METHOD}

\begin{abstract}
The crisis and its reading necessarily entail a sense of negativity, as a method and possibility to understand its terms and its extension. The negativity, that is a movement from the sociability placed by the value form, breaks the premise that the space proposed as simultaneity and replacement of the value terms, presents itself as a rearrangement strategy for the critical state. Thus the crisis, resulting in the level of possible in the disaster, would find into the governance while its maintaining while critical state, introducing the idea of crisis management, and negatively, deepening this toward the catastrophic.
\end{abstract}

Key Words: critical state; catastrophe; governance; negativity; simultaneity.

\section{Introdução}

A crise contemporânea pode ser lida de várias formas. No tocante aos discursos predominantes sobre as crises, elas geralmente dizem respeito a formas conjunturais, ou seja, "passariam" no momento em que os termos que produzem tais crises se reajustassem, se readequassem e reconstituíssem o movimento "normal" e "costumeiro". Neste período atual, a ideia ou noção de crise está geralmente relacionada ao viés econômico; no entanto, a crise se estende a outros domínios da vida social: a arte, a cultura, as relações interpessoais, a educação, a saúde etc. Seria uma crise de tudo, mas a ideia reiterada de crise ainda conduz a uma percepção de que, passada a crise, tudo volta ao normal. Há que se problematizar, contudo, a própria ideia de crise.

Assim sendo, vamos a um possível fundamento: sua negatividade. Poder-se-ia partir do pressuposto de que a crise revela os termos de uma sociabilidade - a do mundo da mercadoria - que não se comporta sem que haja o espectro de sua autodissolução.

Poderíamos supor que a "crise" resulta do fato de que os elementos da vida social recusaram os laços que os uniam, afirmando-se cada um por si mesmo, de modo autônomo: demografia galopante, técnicas desconectadas, ambições sem limites, cientificismo delirante. A 'crise' seria inicialmente não crise de autoridade no sentido vulgar, mas crise da

* Graduado (2001), Mestre (2008) e Doutorando (desde 2009) do Departamento de Geografia da FFLCH-USP, vinculado ao Laboratório de Geografia Urbana (Labur).E-mail: marciorufis@yahoo.com.br 
unidade política tendo e retendo os elementos da vida civil. (LEFEBVRE, 2009, p. 140).

Henri Lefebvre, importante pensador francês, possui uma vasta obra sobre vários domínios da vida social contemporânea. Entre suas preocupações principais, destacase a ideia da "reprodução das relações sociais de produção", que aparece em várias de suas obras. No modo de produção capitalista, não basta que as relações sociais se ponham enquanto sociais ${ }^{1}$, ou seja, sua efetivação pode ser lida no tocante à impossibilidade latente dos próprios termos de sua reprodutibilidade. A reprodução ampliada do capital contém, dentro de sua lógica intrínseca, a objetivação de seu outro, comporta em si a sua autodissolução. É justamente pelo fato de ser inerentemente crítico que 0 capital se expande desmesuradamente a todos os recônditos possíveis, em termos espaciais e temporais. No entanto, a propósito do espaço-tempo, tal noção também reporta à questão da inteligibilidade moderna, já que a compreensão de que existiria, apesar do pensamento, o "mundo físico", a "natureza", o "tempo" etc., remete-nos à problemática do moderno, que necessariamente nos conduz à compreensão da dialética dos termos desse moderno.

O moderno pode ser lido a partir da contradição, e tal contradição a partir de um dos fundamentos do mundo contemporâneo: o valor e a forma-valor, expressas no

\footnotetext{
1 A esse respeito, Georg Lukács, em sua História e Consciência de Classe, traça uma interessante discussão sobre a socialização da sociedade, o mesmo que sua absolutização no domínio da consciência humana. "O homem torna-se - no verdadeiro sentido da palavra - ser social. A sociedade torna-se a realidade para o homem. Desse modo, somente no terreno do capitalismo, da sociedade civil, é possível reconhecer a sociedade como realidade." (LUKÁCS, 2003, p. 96, grifo nosso)
}

movimento geral do mundo da mercadoria e suas determinações qualitativas e quantitativas.
A mercadoria que se encontra na forma equivalente é uma qualidade e também uma quantidade, mas não um quantum, ela não tem determinação quantitativa. É a inscrição da mercadoria que se encontra na forma relativa que introduz um quantum, mas este é um quantum da forma relativa. Para inscrever esse quantum se necessita uma qualidade que se preste ao máximo a ser representada como grandeza. Isto é, uma qualidade tão próxima quanto possível de uma quantidade (a distinguir de um quantum). Uma qualidade, cujas partes sejam homogêneas como as unidades da quantidade, e que seja assim divisível como uma quantidade. Uma qualidade, que embora tenha determinações segundas, funciona como se tivesse só determinações primeiras, isto é, determinações geométricas. Para encarnar esse universal concreto que é o dinheiro, é preciso em suma uma matéria em que cada elemento contenha em si mesmo a generalidade. Mas a universalidade concreta vem com a posição, a "generalidade concreta" só a prepara. (FAUSTO, 1997, p. $70-$ 71)
O dinheiro, realizando-se como o equivalente universal, o mediador necessário ao movimento geral da realização $d a$ mercadoria, é a cristalização do valor e sua efetividade no reino da troca, a mediação necessária entre a qualidade e a quantidade, o amálgama entre a indeterminação e a determinação. A troca, pressupondo a equivalência, eleva o dinheiro à categoria de universalidade e nos remete à sua efetividade enquanto tal.
O dinheiro só se efetiva se desrealizando e só se realiza se "desefetivando" e isto já nos limites mesmos da circulação simples. Este é - sentido da alternância entre a presença representada (pensada) do objeto não simbólico (medida de valor), e da presença real do objeto (no limite) simbólico (meio de circulação). (Ibid., p. 121) 
O jogo entre a efetividade/desrealização realização/"desefetivação" do dinheiro e da mercadoria pressupõe a dialética intrínseca ao movimento do capital: sua simultaneidade e o reino das aparências e ilusões decorrentes do mundo da mercadoria e da forma valor. O valor se efetiva na formavalor, que, socialmente posta e reposta, conduz à reprodutibilidade dos termos de sua sociabilidade decorrente. Tal sociabilidade, assentando-se nas formas abstratas da mercadoria, é apontada por Marx, em "O Capital", na fórmula trinitária: capital - lucro (lucro do empresário + juros); terra - renda da terra; trabalho - salário (MARX, 1972, p. 754). Essa fórmula é o indicativo das formas de produção e reprodução de um sistema universal produtor de mercadorias, que, assentado na lógica e ethos do trabalho, reverbera o automovimento do dinheiro (KURZ, 1996, p. 27).

Sobre o trabalho, transita-se entre sua ontologia e sua negação: a luta (fetichista?) entre "o capital" e "o trabalho", relação até mesmo admitida como uma contradição ou ainda um par dialético advindo da própria tautologia decorrente da efetividade do valor e da forma-valor, se realiza e se acirra no domínio do período financeirizado do capitalismo. Produz-se em escala cada vez mais ampliada o "maisdinheiro" sem que haja, necessariamente, produção de valor: este é o fundamento do capital fictício aventado por Marx. "Desperdiça-se" (nega-se?) trabalho, tempo, recursos humanos e materiais em nome da afirmação do valor, que não mais se efetiva. O trabalho (abstrato e concreto), fundamento societal interposto ao seu ethos, categoria angular no automovimento do dinheiro, parece ser negado e impossibilitado pelo próprio desenvolvimento das forças produtivas. A queda tendencial da taxa de lucro e o dispêndio do trabalho vivo precarizado ou, ainda, o fim do trabalho decorrente de tal tendência, se realiza, cada vez mais criticamente, no período contemporâneo. As classes sociais, criadas e reproduzidas a partir desse modo de produção, encarnam a luta entre as categorias do capital: a chamada luta de classes.

Se a luta de classes se tece em torno da apropriação dos critérios da produção e da distribuição da riqueza social, o sistema político a reafirma quando uma parte dele denuncia a contradição por meio da qual essa riqueza se performa, ou a nega quando converte $o$ exercício da política na negociação contínua do status quo, no jogo positivo pelo poder em si mesmo, sem que a questão da justiça social, da ponderação de quem está se efetivando por meio dele e de quem está sendo excluído dele, acompanhe passo a passo seu movimento. Não é então desse ponto de vista, do alcance da visão e da prática política, que se avaliam as análises de sentido que tentam acompanhar o desdobramento das categorias do modo de produção capitalista? Qual é, porém, o sentido da luta de classes, a luta pelo controle da norma, numa sociedade em que a norma fibrilou, serve para marcar intervalos cujo espaço intermediário, contudo, é preenchido por decisões ad hoc? (GIANOTTI, 2000, p. 333)

Estendendo um pouco mais o

questionamento colocado acima, como podemos estabelecer um vínculo entre a luta de classes (decorrente, suponhamos, da relação contraditória entre o capital e o trabalho) e a tendência contemporânea do "fim do trabalho"? O pensador alemão Robert Kurz (1996) escreveu, há cerca de vinte anos, um instigante ensaio sobre o fim do mundo socialista em fins da penúltima década do século XX e a aparente "vitória" do mundo ocidental. Uma de suas teses é que o que se mostra como a realização do ideal burguês - o "fim da história" - na verdade é 
a evidência cabal do fim deste mesmo mundo

burguês: trata-se do colapso da modernização. Neste colapso, que pode ser lido inclusive como processual, as simultaneidades se interpõem de modo cada vez mais acelerado, dado que a lógica da reprodução tautológica do dinheiro (essa "prisão" moderna) necessita eliminar as chamadas barreiras espaço-temporais para que se realize todo o movimento mundial do capital. As simultaneidades dizem respeito, portanto, às crises e às respostas a essas crises, de modo que os termos da crise financeira internacional de 2008, por exemplo, foram vistos até mesmo como um momento anterior à provável "crise final" e "generalizada" do capitalismo. No entanto, aparentemente, essa crise não se generalizou em escala mundial, na profundidade que se prenunciava, até este momento [2011], pois as formas de ser do mundo financeirizado, tendo acelerado as simultaneidades, se realizam em espaços-tempo onde ainda pode haver a produção (fictícia) de valor: o agronegócio, o mercado imobiliário, as guerras etc., todas formas passíveis de recompor os termos fundantes do capital em seu estágio financeirizado.

\section{Colapso, catástrofe e governança.}

Como se pode perceber, parece que não há limites éticos ou quaisquer que sejam para a sanha autorreprodutiva do capital. Sua reprodução ampliada, necessária à sua própria efetividade, reitera no campo social o sangue, as veias e o oxigênio do processo grandemente subjetivado que é o capital. 0 valor precisa se afirmar e as formas de fetiche também necessitam se reproduzir no campo ético e estético do mundo ocidental.

o espaço e a espacialidade, que podem ser lidos como método, possibilita restituir a simultaneidade inerente às categorias e conceitos do moderno e da modernização. No tocante à geografia, podemos traçar que as tendências físicas ou fisiocratas $^{2}$ de compreensão da realidade social parecem não serem suficientes na compreensão dos termos críticos de uma realidade crítica, dialética, pulsante. 0 espaço é dialético quando se considera sua simultaneidade, daí a proposta de consideralo um método, para além da leitura fisicalista do espaço. Da mesma forma que o tempo, categoria perfeitamente discutível quando se o trata enquanto ontologia, só comporta a dialética quando se esfuma a barreira do sucessório. Desse modo, as categorias que regem o capital e o mundo moderno não se resolvem na forma banal do espaço-tempo físico, pois tal forma se prende demasiadamente às categorias fetichizadas da consciência humana moderna.

A instauração do moderno, processo doloroso para grandes parcelas da humanidade, transformou sobremaneira as formas sociais de reprodução e modo de inteligibilidade da realidade social. De tal maneira que, ao afirmar uma sociedade dividida em classes, necessária à reprodutibilidade do capital, cria uma positivação e absolutização do social,

2 O domínio da Física, importante corpus de conhecimento da época contemporânea, marca sobremaneira as leituras da realidade social. De acordo com as discussões desenvolvidas no início do curso, as concepções físicas nada mais traduziriam do que a forma fetichista necessária de consciência, pois permitiriam pensar contradições do moderno como não-contradições. A Física, interposta ao campo da Economia Política clássica, redundou na Fisiocracia (o valor estaria na multiplicação das sementes das plantas, no domínio da agricultura, naturalmente dado), tão duramente criticada por Marx em várias de suas obras, desde seus primeiros diálogos com os economistas políticos, em seus textos mais antigos. Este fora um dos argumentos centrais interpostos à disciplina "Modernização e Contradições Espaço-Temporais", ministrada pelo Prof. Dr. Anselmo Alfredo, no segundo semestre de 2010. 
conforme afirmamos anteriormente. A positivação, marca fetichista de um modo que necessita constantemente se afirmar por conter intrinsecamente sua forma negativa, é a forma necessária de justificativa do valor: o "progresso". A acumulação primitiva e a ampliada (ambos sucessórios e simultâneos) é a marca de "uma enorme coleção de mercadorias", conforme apontado por Marx na primeira frase do livro I d'O Capital e a ideologia do progresso é o mesmo do ethos do trabalho, e não se apresenta como a ideologia da crise e do crítico, o outro desse mesmo progresso.

No entanto, a crise vem, quer queira quer não, pelo simples fato da crise ser. E quando a crise vem (porque é), aparecem as mais variadas técnicas, as ciências do espaço, as politicas públicas e a governança. A partir daí, a crise produz a "ideologia da crise", que não é a resolução dessa crise (porque ela é irresolúvel, já que é a própria realidade moderna), mas o seu postergar. "Postergando" a crise e seus termos, vive-se um "estado crítico", termo belamente apontado por Lefebvre para compor esse movimento.

Em vez de dizer "crise", seria necessário dizer estado crítico do mundo moderno em geral, do modo de produção estatista em particular. O estado crítico não provém nem do econômico tomado à parte, nem do político isolado a título de instância. Esse estado crítico tem seu ponto de partida no social como tal: o que Hegel e Marx nomeiam de sociedade civil. A crise no sentido usual iria do econômico ao político. O estado crítico tem sua origem e, sobretudo, seus efeitos não nas organizações ou instituições, mas nas relações que sustentam essas instituições: a família, a escola, as relações entre as pessoas, os "valores", as "normas", as "ideologias". Esmagada, encurralada entre o político e o econômico, essa vasta região sofre de um mal crônico. (LEFEBVRE, id., p. 145)
O estado crítico se manifesta de várias formas no contemporâneo. Uma das formas que podemos apresentar assenta-se no modo no qual alguns movimentos sociais (institucionalizados ou não) constroem suas pautas de reivindicações. Os limites que se colocam à ação prática desses movimentos são inúmeros, o que se traduz na fórmula: "o que se pode fazer diante do progresso? Resistir da forma que dá e tentar retirar algum benefício, ora essa! ${ }^{3}$ Pode parecer uma enorme simplificação do sentido dessas lutas sociais, dado o alcance e a extensão de certos movimentos sociais e suas justas reivindicações; mas há que se reconhecer que, em uma boa parte deles, o Estado é uma forte referência, e a dicotomia Estadomercado, conforme apresentado por Kurz (Ibid., p. 20) é uma realidade nesses movimentos, posto que reivindicar o Estado, os direitos civis, a moradia etc, aparece como uma reivindicação à existência e à mínima possibilidade de vida, onde o mínimo é a tônica fundante na lógica da equivalência do mundo da mercadoria. E muitos desses movimentos sociais são um retrato das consciências individuais, que reconhecem a

3 Como exemplo, listamos um encontro de lideranças comunitárias do distrito paulistano Raposo Tavares, do qual participamos no mês de outubro de 2010. Esse encontro, promovido pelo Educandário Dom Duarte, instituição filantrópica vinculada à Liga Solidária, tinha como objetivo manifesto a elaboração de diretrizes para a construção de um "futuro comum" desejável ao distrito Raposo Tavares. Trata-se de uma região cuja precificação da terra já é uma dura realidade para as populações mais pobres, que começam a sentir seus impactos: ameaças de despejos de "ocupações irregulares", incêndios em favelas, empreendimentos imobiliários de alto padrão contrastando com a crônica falta de moradia adequada para as populações locais etc. A tônica do encontro foi: "como podemos lidar com esses problemas?", "vamos exigir do poder público que...", "é necessário um plano de moradia e transporte por parte do poder público..." Não se trata, aqui, de culpabilizar as pessoas envolvidas nessa justíssima pauta de reivindicações, mas de demonstrar o limite prático desses movimentos: a reivindicação do Estado "justo", "redistributivo" etc. 
positividade do mundo da mercadoria, pois este aparece como o absoluto, na prática e na teoria.

Lefebvre costuma tratar dessa realidade de várias maneiras. Em La conscience mystifiée [A consciência mistificada] (1999), obra publicada originalmente em 1936, às vésperas da Segunda Guerra Mundial, o autor, ao lado de Nobel Gutermann, discorre sobre as formas de consciência social e política emergentes na Europa daquele momento, em plena ascensão do nazi-fascismo. Ao nível da consciência humana, o tratamento dado pelos autores se funda na consciência privada e na consciência mistificada; elas traduzem uma impossibilidade ou a ilusão da existência prática do sujeito numa realidade cujas categorias reificam a relação sujeito-objeto, fruto também do moderno. Ambas, em termos "privados" (vida "privada" e consciência "privada" proveriam da mesma raiz etimológica, segundo os autores [Ibid., p. 71]) ou sociais (a consciência mistificada, se realizando necessariamente nos termos da mistificação, dada sua necessidade de repor o "sujeito" da "época sincera" [Ibid., p. 136]) constituem os termos dramáticos de uma realidade social onde a falência do Logos, tão aventada por Lefebvre, apresenta-se como a reiteração (violenta) do Estado nacional absoluto do nazi-fascismo.

Essa reiteração do Estado e toda sua sorte de violências é também a redundância da tecnocracia, esta sempre presente, acompanhando o modus operandi da "sociedade civil organizada", do "Estado de direito", da "administração pública" etc. A tecnocracia estatal é a forma contemporânea de administração da crise e a ideologia das crises, conforme apontado anteriormente, também produz o seu outro, ainda nos termos fetichizados: a governança. O Estado "bom", "justo" e "democrático" é uma das maiores armadilhas da contemporaneidade, posto que se absolutiza no discurso e práticas socialmente "aceitas" e "reconhecidas" como "boas práticas" de governo. Nesse contexto de desistência da crítica ao valor e à formavalor, as categorias centrais do mundo da mercadoria não são, de modo algum, passíveis de problematização ou até mesmo de discussão no reino da "boa administração", e os "problemas sociais" se apresentam como "conhecidos" e sua "solução" já pronta. São discursos absolutizadores, potentes, reconfortantes, apaziguadores e profundamente (admitidamente!) reformistas e românticos, com adeptos tanto das "direitas" quanto das "esquerdas" político-institucionais, acadêmicas etc. São a produção e reprodução da ideia de que a classe média, com sua "qualidade de vida" ("boa" saúde, renda, educação etc.) deve ser a classe dominante, o devir social, o futuro. A governança é o reiterativo da ilusão do sujeito, e uma boa discussão sobre devir do sujeito-objeto idêntico é apontada por Lukács no prefácio escrito, em 1967, para sua obra História e consciência de classe (2003), que fora publicada originalmente em 1923.

Na História e consciência de classe, [...], [a realização do sujeito-objeto idêntico] é um processo históricosocial que culmina no fato de que 0 proletariado realiza essa etapa na sua consciência de classe, tornando-se o sujeito-objeto idêntico da história. [...] Mas será que sujeito-objeto idêntico é mais do que uma construção puramente metafísica? Será que um sujeito-objeto idêntico é efetivamente produzido por um autoconhecimento, por mais adequado que seja, mesmo que tenha como base um conhecimento adequado do mundo social, ou seja, será que ele é produzido numa consciência de si, por mais completa que seja? Basta formular a questão com precisão para respondê-la negativamente. Pois, mesmo que o 
conteúdo do conhecimento possa ser referido ao sujeito do conhecimento, o ato do conhecimento não perde com isso seu caráter alienado. (LUKÁCS, 2003, p. 24 - 25, grifo nosso)

Poderia a alienação ser compreendida, a partir dessa passagem, como condição necessária para a efetividade da reificação ${ }^{4}$ e da fetichização, pilares do mundo fantasmagórico da mercadoria? Essas três formas de obnubilação da consciência e da práxis humana, postas como mediação necessária, constituem o negativo da própria consciência de classe, já que as classes sociais se constituem como a corporificação ou a encarnação das categorias do capital ${ }^{5}$. Ainda a propósito desse debate, o próprio Lukács incorre em um mea-culpa, quando aponta nesse mesmo prefácio que objetificação não é a mesmo que a alienação, sendo a primeira uma "forma humana universal de intercâmbio dos homens entre si, [que] não é boa nem é má" (Ibid., p. 27) e a última uma deturpação e desfiguração da essência humana pelo ser social, o surgimento da relação objetivamente social da alienação. Desse modo, há que se reconhecer que a superação de certas formas de alienação poderiam conter seu pressuposto negativo, que seria o surgimento de outras formas obnubiladas da consciência e da práxis humana.

Essas formas obnubiladas repõem o estado crítico apontado por Lefebvre, que

\footnotetext{
4 "A reificação é [...] a realidade imediata e necessária para todo homem que vive no capitalismo, e só pode ser superada por um esforço constante e sempre renovado para romper na prática a estrutura reificada da existência, mediante uma referência concreta às contradições que se manifestam concretamente no desenvolvimento global, e com a conscientização do sentido imanente dessas contradições para a totalidade do desenvolvimento." (LUKÁCS, 2003, p. 391)

${ }^{5}$ Vide a fórmula trinitária e seu correspondente na práxis social, conforme apontado anteriormente.
}

pode ser considerado o prenúncio do estado revolucionário, cujo fundamento se assenta na negatividade absoluta, comportando o sentido de catástrofe.

[A última crise] é a catástrofe, jamais estudada como tal, ainda que frequentemente anunciada pelo marxismo apocalíptico (Rosa Luxemburgo e outros). Em suma, na crise revolucionária se rompem as cadeias de equivalências: com a lógica da mercadoria, aquela da reprodução e da separação, aquela do exercício de um poder exterior e superior à sociedade (civil). [...] A teoria das catástrofes permite explicar as estruturas e justifica dinamicamente seu aparecimento, sua estabilidade, seu fim. [...] Essa teoria é qualitativa, ignorando as considerações de escala, assim como as leis somente quantitativas. (LEFEBVRE, 2009, p. 148 - 152)

A catástrofe, o ponto de plena ruptura com as estruturas e formas precedentes e seu equilíbrio, comporta o momento da crise generalizada. Sendo um momento e ao mesmo tempo um processo cuja duração é indeterminada, a catástrofe seria a crise de todas as crises, o momento em que as equivalências se desfazem, em que as formas de sociabilidade já não são mais reprodutíveis nem suportáveis. (ibid., p. 148) No entanto, a latência da catástrofe se esfuma quando o estado crítico permanece se reproduzindo enquanto tal, por intermédio das leis "seguras" e "eficientes" da governança global. E, conceitualmente, do que se trata? A governança, tema de estudo em algumas áreas da Ciência Política e das Relações Internacionais,

diz respeito aos meios e processos que são utilizados para produzir resultados eficazes. [...] O conceito compreende a ação conjunta de Estado e sociedade na busca de soluções e resultados para problemas comuns. Mas e inegável que o surgimento dos atores não-estatais é central para o desenvolvimento da ideia e da prática da governança. (GONÇALVES, 2006, pp. 13 e 14) 
A coletividade abstrata intrínseca a esse conceito incorre na figura igualmente abstrata da "sociedade civil organizada", que faria pari-passu ao Estado o papel de administrador público. A coletivização abstrata, no domínio dos "atores nãoestatais", é a mesma face da moeda que ratifica o Estado e azeita as engrenagens sociais e políticas que movimentam o grande maquinário produtivo mundial. Trata-se da ratificação do fetiche do Estado, o mesmo que toda a sorte de fetichização do mundo da mercadoria e sua efetividade no reino das abstrações tornadas concretas.

Todos os documentos apontam para a necessidade da construção da governança ${ }^{6}$ seja no plano do Estado nacional, seja nas organizações internacionais (para não falar de empresas privadas). Com isso, fica implícito que a palavra conte um elemento positivo: governança necessariamente é a boa governança. Onde ficam, entretanto, os erros e falhas no processo de sua construção? A má governança seria simplesmente a 'ausência' de governança, ou há espaço para uma discussão maior sobre os métodos e planos de sua construção e implementação? (Ibid., p. 7)

A dicotomia entre a "boa" e a "má" governança nos remete à discussão sobre a identidade entre a falha do Estado e a falha do mercado proposta por Robert Kurz, onde é apontada a falsa dicotomia entre ambos, já que "a forma de reprodução social da modernidade perdeu completamente sua capacidade de funcionamento e de integração" (KURZ, 1996, p. 234). Então, por que se recorre à governança e às formas de administração da crise, se ambos falham, já que a modernidade e suas categorias (re)produtivas encampam indisfarçável

6 Refere-se a documentos oriundos do Banco Mundial e de outros órgãos supranacionais que delimitam e balizam teórica e praticamente a governança no domínio da administração pública mundial. colapso (ou o estado crítico tendendo ao revolucionário-catastrófico)? Seria a tentativa de manter o ar-condicionado do cardápio de soluções advindas das técnicas políticoeconômicas e toda sua sorte de especializações no mundo acadêmico e institucional? Ainda, seriam os termos da incessante busca pelo quotidiano, onde a falta do Estado, da renda, da moradia e da alimentação etc. almeja para vastas populações do mundo contemporâneo a felicidade humana o ingresso à "sociedade civil", à "cidadania" ou à "democracia"? Podese dizer que o colapso ou a catástrofe do "mundo ocidental", do Iluminismo, das artes, do Logos europeu-ocidental etc. admitiria, como já admitira em momentos críticos precedentes, o recurso ao fácil mundo da utopia e do visionarismo? 


\section{REFERÊNCIAS BIBLIOGRÁFICAS}

FAUSTO, Ruy. Dialética marxista, dialética hegeliana: a produção capitalista como circulação simples. Rio de Janeiro: Paz e Terra / São Paulo: Brasiliense, 1997. (Oficina de filosofia)

GIANOTTI, José Arthur. Certa herança marxista. São Paulo: Companhia das Letras, 2000.

GONÇALVES, Alcindo. o conceito de governança. In: CONGRESSO NACIONAL DO CONSELHO NACIONAL DE PESQUISA E PÓS GRADUAÇÃO EM DIREITO (CONPEDI), 15., 2006, Manaus. Disponível em: www.conpedi.org.br/manaus/arquivos LAnais/Alcindo\%20Goncalves.pdf, acesso em 21 nov. 2010.

GUTERMANN, Norbert e LEFEBVRE, Henri. La conscience mystifiée. Paris: Éditions Syllepse, 1999.
KURZ, Robert. 0 colapso da modernização: da derrocada do socialismo de caserna à crise da economia mundial. Rio de Janeiro: Paz e Terra, 1996. $4^{a}$ ed.

LEFEBVRE, Henri. Da teoria das crises à teoria das catástrofes. Tradução: Anselmo Alfredo, Carolina Massuia de Paula e Thomas Ficarelli. GEOUSP Espaço e Tempo. São Paulo, no 25, pp. $138-152,2009$.

LUKÁCS, Georg. História e Consciência de Classe. Estudos sobre a dialética marxista. São Paulo: Martins Fontes, 2003.

MARX, Karl. Cómo se convierte la ganancia extraordinaria en renta del suelo. In: El Capital. Crítica de la economía política. Tomo III. México: Fondo de Cultura Económica, 1972. 